E3S Web of Conferences 1, 33005 (2013)

DOI: $10.1051 / \mathrm{e} 3$ sconf/20130133005

C) Owned by the authors, published by EDP Sciences, 2013

\title{
Mobility and toxicity of heavy metals in bottom sediments of Rybnik reservoir
}

\author{
${\text { A. } \operatorname{Baran}^{1} \text { and M. Tarnawski }}^{2}$ \\ ${ }^{1}$ Department of Agricultural and Environmental Chemistry, University of Agriculture in Krakow, al. A. Mickiewicza 21, \\ 31-120 Krakow, POLAND, Agnieszka.Baran@ur.krakow.pl \\ ${ }^{2}$ Department of Water Engineering ${ }^{2}$, University of Agriculture in Krakow, al. A. Mickiewicza 24/28, 30-059 Kraków, \\ POLAND,rmtarnaw@cyf-kr.edu.pl
}

\begin{abstract}
Heavy metals are one of the most important factors among many others in biosphere pollution. Mobility and toxicity of metals associated with bottom sediments are generally affected by metal speciation and sediments compositions. The aims of this study were to investigated the distribution of metal speciation in sediment collected from Rybnik dam reservoir and to asses their toxicity for aquatic ecosystem. The speciation analysis of metal was performed using the three-step method of sequential fractionation by means of the modified BCR technique. Toxicity assestement of the bottom sediment samples was preformed using tests: Phytotoxkit ${ }^{\mathrm{TM}}$, Ostarcodotoxkit $\mathrm{F}^{\mathrm{TM}}$, Microtox ${ }^{\circledR}$. According to the above results, the mobilization potential of heavy metals in sediments in a decreasing order (fraction $\mathrm{I}+\mathrm{II}$ ): $\mathrm{Zn}>\mathrm{Cd}>\mathrm{Ni}>\mathrm{Pb}>\mathrm{Cu}>\mathrm{Cr}$. According to the Risk Assessment Code (RAC), the sediments having at low risk ( $\mathrm{Pb}, \mathrm{Cu}, \mathrm{Cr})$, medium risk ( $\mathrm{Cd}, \mathrm{Ni})$ and high risk $(\mathrm{Zn})$. The analysis of all sediment samples collected from the suited reservoir showed that Classes III (acute hazard $50 \% \leq \mathrm{PE}<100 \%$ ) was represented by $80 \%$ samples.
\end{abstract}

Key words: metal speciation, mobility, sediment toxicity, battery biotests

\section{Introduction}

Bottom sediments accumulated in water reservoirs constitute a very important part of ecosystems, play an important role in their functioning and element cycling between individual components of soil and groundwater system. Bottom sediments play the role of a natural filter and are indicators of the degree of environmental degradation. Heavy metals constitute a significant part of these pollutants, which at some concentrations may be toxic for aquatic ecosystem (Baran et al. 2011). Mobility and toxicity of metals associated with bottom sediments are generally affected by metal speciation and sediments compositions (Lin et al. 2003, Madeyski et al. 2009). Metals in exchangeable, carbonate-bound, and $\mathrm{Fe} / \mathrm{Mn}$ oxide-bound speciation are considered to be more mobile and bioavailable. The organic matter-bound and residual metals are stable and non-bioavailable. An assessment of the environmental risks requires the measurement not only the total contents of heavy metal in sediment, but also for the amounts in each binding form. MankiewiczBoczek et al. (2008) described a need to apply a battery biotests for integral and ecologically meaningful evaluation of hazard of water and sediments.

The aims of this study were: (1) to investigated the distribution of metal speciation in sediment collected from dam reservoir in the conditions of anthropomixion, (2) to asses their toxicity for aquatic ecosystem. To obtained information may provide a better understanding of environmental risks of heavy metal in sediment.

\section{Materials and Methods}

In this study, surface sediment $(0-10 \mathrm{~cm})$ samples were collected from four stations located in Rybnik reservoir (Southern Poland). In order to get a representative samples for each stations, several samples were collected and mixed together. Sediments were sampled using an Ekman dredge. Once in the laboratory, the sediment samples were air dried, homogenized in a mortar, sieved to pass through a 2-mm stainless steel sieve and stored in polyethylene containers. The speciation analysis of metal was performed using the three-step method of sequential fractionation by means of the modified BCR technique (Mossop and Dawson 2003): fraction I - exchangeable and acid soluble fraction, extractable with $\mathrm{CH}_{3} \mathrm{COOH}$ at $0.11 \mathrm{~mol} \cdot \mathrm{dm}^{-3}$ concentration and $\mathrm{pH}=2$; fraction II forms associated with free Fe and Mn oxides, extractable with $\mathrm{NH}_{2} \mathrm{OHHCl}$ at $0.5 \mathrm{~mol} \cdot \mathrm{dm}^{-3}$ concentration and $\mathrm{pH}=1,5$; fraction III - forms bonded to organic matter, extractable with hot $30 \% \quad \mathrm{H}_{2} \mathrm{O}_{2}$ and then the mineralization products re-extracted with $\mathrm{CH}_{3} \mathrm{COONH}_{4}$ 
at $0,5 \mathrm{~mol} \cdot \mathrm{dm}^{-3}$ concentration and $\mathrm{pH}=2$; fraction $\mathrm{IV}-$ residual forms, the difference between the total metal content and sum of the above three fractions. Total contents of heavy metals in the sediments were assessed after hot mineralization in a mixture of $\mathrm{HNO}_{3}$ and $\mathrm{HClO}_{3}$ acids (3:2). Metal concentrations in the obtained solutions were assessed using ICP-OES method on Optima 7300 DV PerkinElmer. Toxicity assestement of the bottom sediment samples was preformed using direct - contact tests consisting of 5 species. The battery was composed of test species representative of different trophic levels of the food chain: producers (Sorghum saccharatum, Lepidium sativum, Sinapis alba - Phytotoxkit $^{\mathrm{TM}}$ ), consumer (Heterocypris incongruens - Ostarcodotoxkit $\mathrm{F}^{\mathrm{TM}}$ ) and decomposer (Vibrio fischeri - Microtox ${ }^{\circledR}$ ). The toxicity data has been classified according to the hazard classification (Persoone et al. 2003).

\section{Results and Discussion}

\section{Chemical speciation}
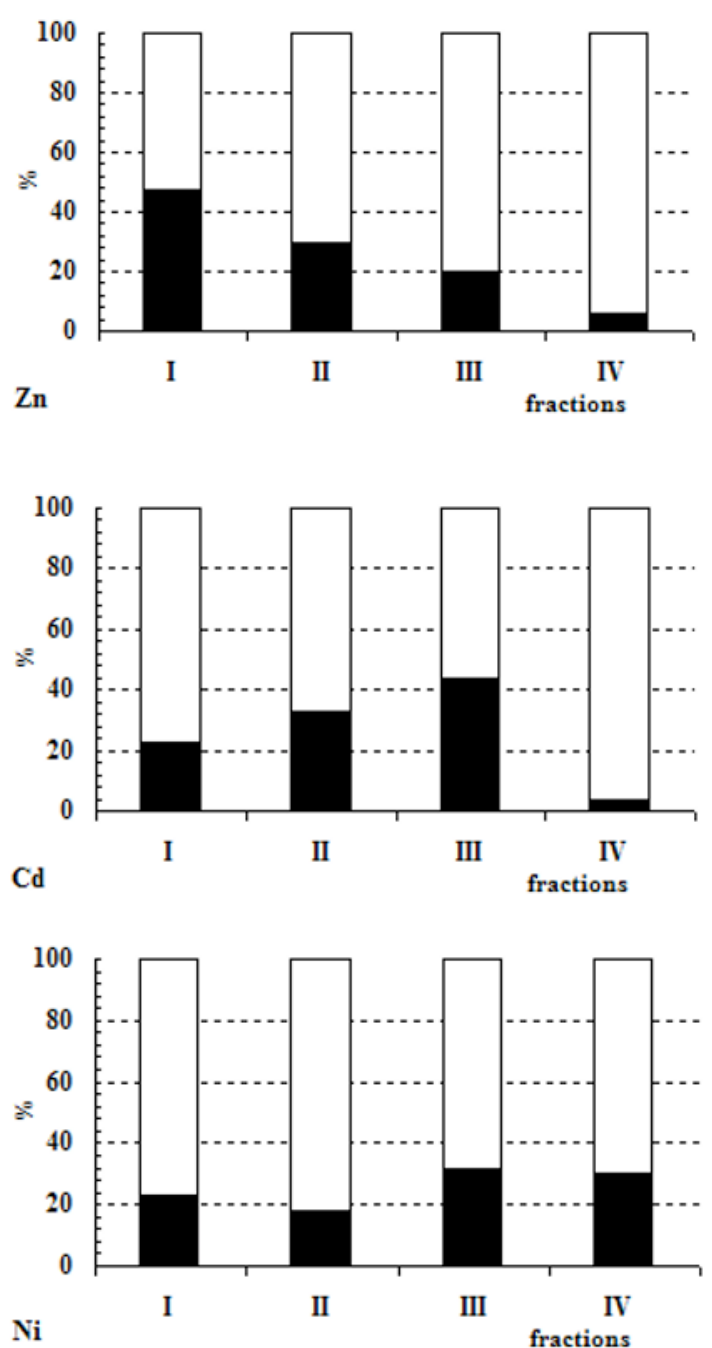

Based on the results shown in Figure 1, it was found that $\mathrm{Zn}$ mainly existed as exchangeable and acid soluble fractions (fraction $\mathrm{I}-47 \%$ ) and free $\mathrm{Fe}$ and $\mathrm{Mn}$ oxides fraction (fraction $\mathrm{II}-27 \%$ ). $\mathrm{Cu}$ was predominantly fund organic matter-bound (fraction III - 72\%). The participation of copper bound with the other fractions constituted, as a whole, less than $10 \%$ (fraction I i II) $20 \%$ (fraction IV). In the examined sediments $\mathrm{Cd}$ was bound first of all, with organic matter (fraction III - 43\%) and free Fe and Mn oxides and (fraction III - 32\%). The participation of cadmium bound with the other fractions constituted was about $22 \%$ with exchangeable and acid soluble fractions (fraction I) and 3\% residual forms (fraction IV). The distribution of $\mathrm{Pb}$ was similar to $\mathrm{Cu}$, being dominated by organic matter-bound (fraction III $62 \%$ ). Participation of $\mathrm{Pb}$ fraction bound with free $\mathrm{Fe}$ and Mn oxides, residual and exchangeable and acid soluble fractions was as follows: $25 \%, 12 \%, 1 \%$ in sediments from the reservoir at Rybnik. Based on the results shown in Figure 1, it was found that $\mathrm{Ni}$ mainly existed as organic matter (fraction III $-31 \%$ ) and residual fractions (fraction IV $-30 \%$ ). The
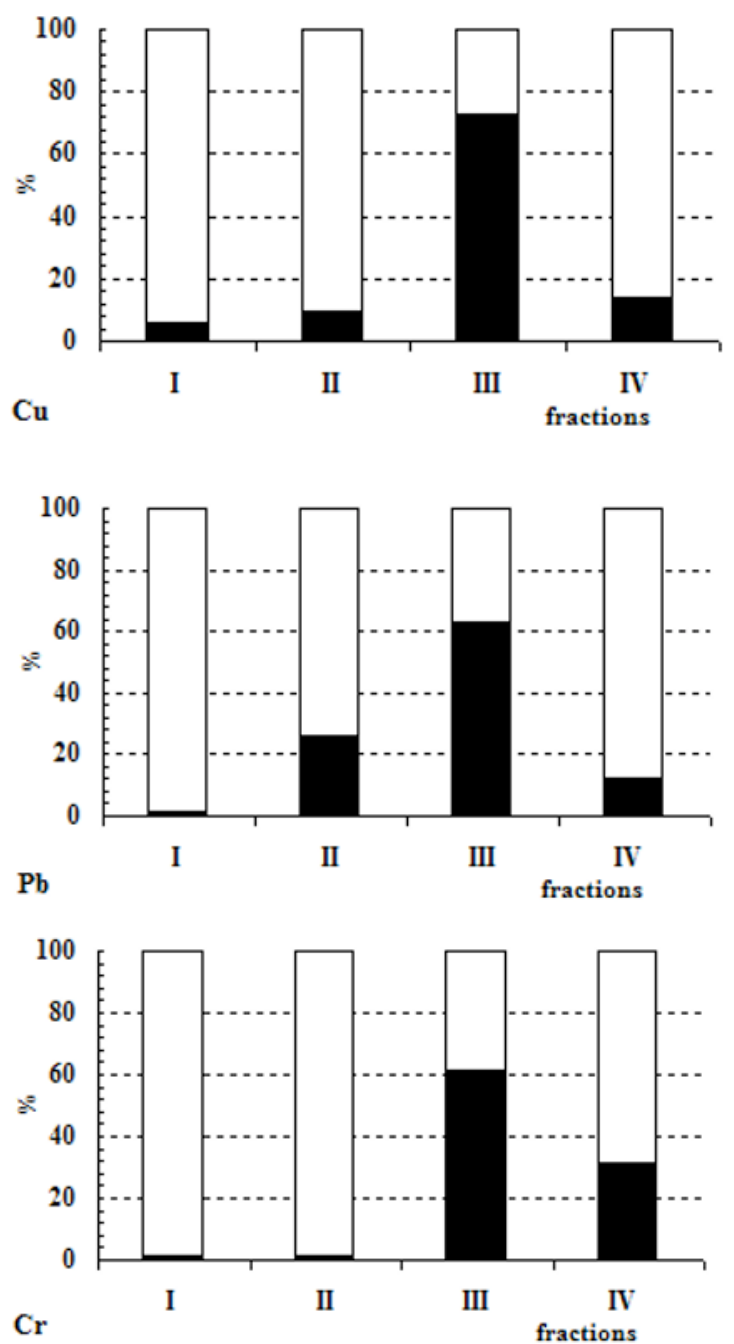

Fig. 1. Example of metal distribution in particular fractions. 
behavior of $\mathrm{Cr}$ was similarly to $\mathrm{Cu}$. A considerable percentage (about $60 \%$ ) of $\mathrm{Cr}$ was mainly found in the residual fraction.

\section{Ecotoxicity test}

For the sediment samples, the highest number of toxic response was observed in the chronic Phytotoxkit ${ }^{\mathrm{TM}}$ with producers Lepidium sativum (24\% responses), Sinapis alba (22\% responses), respectively (Fig. 2). In the other proposed microbiotest with decomposer - bacteria Vibrio fischeri (Microtox ${ }^{\circledR}$ ) and producer Sorghum saccharatum (Phytotoxkit ${ }^{\mathrm{TM}}$ ), the number of toxic response was respectively 20 and $15 \%$. The lowest toxicity was determined in the chronic Ostarcodotoxkit $\mathrm{F}^{\mathrm{TM}}$ with consumer Heterocypris incongruens (Fig. 2).

\section{Conclusion}

The sequential extraction for determination of metal speciation was good alternative for total metal analysis the environmental risks of heavy metals in sediments. According to the above results, the mobilization potential of heavy metals in sediments in a decreasing order (fraction $\mathrm{I}+\mathrm{II}$ ): $\mathrm{Zn}>\mathrm{Cd}>\mathrm{Ni}>\mathrm{Pb}>\mathrm{Cu}>\mathrm{Cr}$. Trace metals in the sediments were associated in the exchangeable fractions from 1 to $23 \%$. Thus according to the Risk Assessment Code (RAC), these sediments were at low risk $(\mathrm{Pb}, \mathrm{Cu}, \mathrm{Cr})$, and medium risk $(\mathrm{Cd}, \mathrm{Ni})$. According to RAC the concentration of $\mathrm{Zn}(47 \%)$ was a high risk. The analysis of all sediment samples collected from the suited reservoir showed that Classes III (acute hazard $50 \% \leq \mathrm{PE}<100 \%$ ) was represented by $80 \%$ samples. In Classes IV (high acute hazard $\mathrm{PE}=100 \%$, in at least one test) was observed only in $20 \%$ analyzed samples.

\section{References}

Baran A., Tarnawski M., Jasiewicz Cz. Assestement of the content and solubility of heavy metals in bottom sediments of Chancza reservoir. Ecol. Chem. Enginer. 2011; 18(7): 941-950.

Lin J.G., Chen S.Y., Su C. R. Assessment of sediment toxicity by metal speciation in different particle size fractions of river sediment. Water Sci. Technol. 2003; 47(7-8): 233-241.

Madeyski M, Tarnawski M, Jasiewicz Cz. Baran A. Fractionation of chosen heavy metals in bottom sediments of small water reservoirs. Arch. Environ. Prot., 2009; 35(3): 47-59.

Mankiewicz-Boczek J., Nałecz-Jawecki G., Drobniewska A., Kaza M., Sumorok B., Izydorczyk K., Zalewski M., Sawicki J.

Application of microbiotest battery for complete toxicity assestement of rivers. Ecotoxicol. Environ. Saf. 2008; 71: 830-836.

Mossop, K. F., Davidson, C. M. Comparison of original and modified BCR sequential extraction procedures for the fractionation of copper, iron, lead, manganese and zinc in soils and sediments. Anal. Chim. Acta, 2003; 478: 111-118.

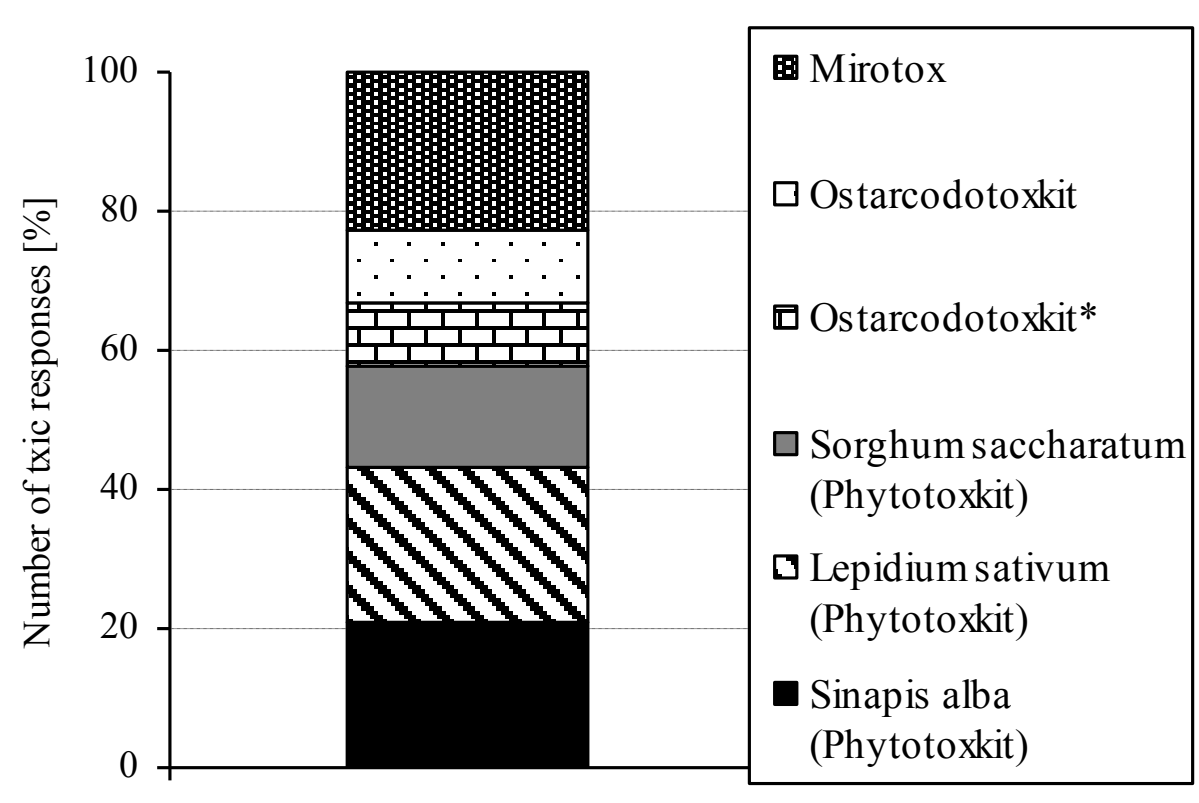

Bottom sediment

Fig. 2. The number of toxic response described for each microbiotest as the percentage from total number of tests (Ostarcodotoxkit* - growth inhibition, Ostracodotoxkit - morality). 
Persoone G., Marsalek B., Blinova I., Törökne A., Zarina D., Manusadžianas L., Nałęcz-Jawecki G., Tofan L., Stepanowa N., Tothova L., Kolar B. A practical and user-friendly toxicity classification system with microbiotets for natural waters and wastewaters. Environ. Toxicol. 2003; 18: 395-402.

\section{Acknowledgements}

Scientific work financed the budget for science Research Grant No. N N305 295037 "Assestement of the possibility of agricultural use reservoir bottom sediments" (2009-2012). 